\title{
Interleukin-1 Synergy with Phosphoinositide Pathway Agonists for Induction of Interleukin-2 Gene Expression: Molecular Basis of Costimulation
}

\author{
THOMAS J. NOVAK, † DAN CHEN, AND ELLEN V. ROTHENBERG* \\ Division of Biology, California Institute of Technology, Pasadena, California 91125
}

Received 4 June 1990/Accepted 24 August 1990

\begin{abstract}
The macrophage-derived cytokine interleukin-1 (IL-1) can provide a second signal with antigen to elicit production of interleukin-2 (IL-2) by helper T cells. The pathway(s) involved remains controversial, with protein kinase $\mathrm{C}$ and cyclic AMP (cAMP) invoked as possible second messengers. In the murine thymoma EL4.E1, IL-1 could synergize with the phosphoinositide pathway, because the cells made higher levels of IL-2 in the presence of IL-1 than could be induced by phorbol ester plus calcium ionophore alone. IL-1 is unlikely to act through a sustained increase in cAMP in these cells because it did not raise cAMP levels detectably and because IL-1 and forskolin had opposite effects on IL-2 gene expression. Inducible expression of a transfected reporter gene linked to a cloned fragment of the murine IL-2 gene promoter was initially increased by IL-1 costimulation, implying that IL-1 can increase the rate of transcription of IL-2. The minimal promoter elements required for IL-1 responsiveness were located within 321 bp of the IL-2 RNA cap site, and further upstream sequences to -2800 did not modify this response. IL-1 costimulation resulted in enhanced activity of both an inducible NF-KB-like factor and one of two distinct AP-1-like factors that bind to IL-2 regulatory sequences. Neither was induced, however, by IL-1 alone. Another AP-1-like factor and NFAT-1, while inducible in other cell types, were expressed constitutively in the EL4.E1 cells and were unaffected by IL-1. These results are discussed in terms of the combinatorial logic of IL-2 gene expression.
\end{abstract}

Interleukin-1 (IL-1) is a potent mediator of cellular function that is produced primarily by activated macrophages (19), and a role for IL-1 in T-cell activation has been demonstrated in a number of experimental systems $(7,8,25)$. In vitro, IL-1 synergizes with mitogenic lectins or anti-T-cell receptor $(\mathrm{TcR})$ antibodies to induce expression of interleukin 2 (IL-2) and IL-2 receptor $\alpha$-chain genes $(13,18,44)$. In these roles, IL-1 can be replaced by tumor-promoting phorbol esters (e.g., 12-O-tetradecanoylphorbol 13-acetate [TPA]) (11). As IL-1 was known to provide a necessary, antigennonspecific signal for T-cell activation (9), this apparent equivalence with TPA initially suggested that its action might result from activation of protein kinase $C$ (28). However, IL-1 does not promote phosphoinositide hydrolysis or cause protein kinase $C$ translocation to an active membranebound form (1). It therefore seems unlikely that its role is to augment the low levels of diacylglycerol produced by TcRmediated phosphoinositide breakdown. More recently, it has been demonstrated that IL-1 treatment of the human T-cell leukemia line Jurkat causes increased production of two protein kinase $\mathrm{C}$ cofactors, phosphatidylserine and diacylglycerol, the latter from hydrolysis of membrane phosphatidylcholine $(23,34)$. However, because Jurkat lacks conventional IL-1 receptors (IL-1Rs) (34), the significance of these results for other $\mathrm{T}$ cells is unknown.

The studies that have reported a costimulatory role for IL-1 have usually demonstrated this effect on cells suboptimally stimulated with mitogenic lectins $(13,15,18,44)$. Several laboratories have obtained results that call into doubt the notion that IL-1 is necessary at all for the

\footnotetext{
* Corresponding author.

$\dagger$ Present address: Section of Immunobiology, Howard Hughes Medical Institute, Yale University School of Medicine, New Haven, CT 06510.
}

high-level production of IL-2 when the TcR signal is optimized. We have shown that when fresh splenic $\mathrm{T}$ cells produce IL-2 in response to TPA and the calcium ionophore A23187, their response is both independent of and insensitive to added IL-1 $(35,36)$. Lichtman et al. (21) have obtained similar results with a panel of cloned antigendependent $T_{\mathbf{H}} 1$ cell lines stimulated with an anti-CD3 monoclonal antibody. Two other groups have shown that longterm $\mathrm{T}_{\mathbf{H}} 1$ (IL-2-producing) lines may lack IL-1Rs altogether $(14,20)$. Thus, these systems do not provide access to any unique pathway through which IL-1 may act.

Recent data suggest, however, that a requirement for IL-1 may reflect the developmental status of a $\mathrm{T}$ cell. These differences are most apparent in induction of IL-2 expression, a response subject to complex regulation $(16,27,32)$. Mature $\mathrm{TcR}^{+}$thymocytes resemble peripheral $\mathrm{T}$ cells in their insensitivity to IL-1 when they are stimulated to produce IL-2 in response to TPA plus A23187. These chemical proxies for mediators of the phosphatidylinositol bisphosphate hydrolysis pathway may be able to induce IL-2 expression in all mature $\mathrm{T}$ cells, for they can also elicit high-level responses in most fresh peripheral $\mathrm{CD}^{+}$cells $(24)$, cells which generally do not express IL-2 mRNA in response to either antigen or mitogenic lectins. In contrast, however, immature $\mathrm{TcR}^{-}$ double-negative thymocytes do not make IL-2 in response to TPA and A23187 at all unless IL-1 is present $(35,36)$. Thus, these immature thymocytes differ from their more mature descendents in two important aspects of their IL-2 inductive signal requirements. First, in these cells, phosphoinositide pathway agonists are insufficient to activate IL-1 expression. Second, they possess a pathway allowing IL-1 effects to synergize with phosphoinositide pathway mediators.

Here we report that the cloned murine thymoma EL4.E1 possesses characteristics of both immature and mature IL-2 producers. Like mature $\mathrm{T}$ cells, it can respond to phorbol 
ester and ionophore alone. In addition, it possesses a trait normally associated with immature thymocytes, namely, responsiveness to IL- 1 as a costimulus with TPA plus A23187. We have used these cells to explore the mechanism by which the synergy between IL-1 and TPA plus A23187 occurs.

\section{MATERIALS AND METHODS}

Reagents. TPA and A23187 were from Sigma or Calbiochem. They were dissolved in dimethyl sulfoxide to final concentrations of $10 \mu \mathrm{g} / \mathrm{ml}$ and $0.37 \mathrm{mg} / \mathrm{ml}$, respectively, and stored in small samples at $-20^{\circ} \mathrm{C}$. Recombinant human and mouse IL-1 $\alpha$ (IL-1) was purchased from Genzyme. The specific activity, as reported by the supplier, was $10^{8} \mathrm{U} / \mathrm{mg}$.

Cells. EL4.E1, a mouse IL-2-producing thymoma cell line (originally donated by V. Paetkau, University of Alberta), and the human T-cell leukemic line Jurkat (generously provided by G. Crabtree, Stanford University) were grown in RPMI 1640 supplemented with $10 \%$ fetal bovine serum, 2 mM L-glutamine, $50 \mu \mathrm{M} 2$-mercaptoethanol, and antibiotics.

Plasmids. The series of pIL2-CAT plasmids containing varying lengths of the mouse IL-2 gene $5^{\prime}$ DNA linked to the bacterial gene for chloramphenicol acetyltransferase (CAT) has been descrited in detail (30). Briefly, cloned fragments of the IL-2 gene 5'-flanking region, all terminating 3 ' at +45 (in the $5^{\prime}$ untranslated region), were ligated to the CAT gene from pTK-CAT in the vector pSP65 (Promega). They are designated pIL2 $(-X)$, where $X$ is the $5^{\prime}$-terminal nucleotide, relative to the IL-2 transcriptional start site, that is present in the construct. All plasmids were purified in $\mathrm{CsC1}$-ethidium bromide density gradients before use.

Transfections and CAT assays. Transfection of logarithmically growing cells was by DEAE-dextran facilitation as described elsewhere (30). In short, cells were washed in serum-free Dulbecco modified Eagle medium with $10 \mathrm{mM} \mathrm{N}$ 2-hydroxylethylpiperazine- $N^{\prime}$-2-ethanesulfonic acid (HEPES; $\mathrm{pH}$ 7.0) (DME/H) and then suspended at $10^{7} / \mathrm{ml}$ in a transfection cocktail containing $250 \mu \mathrm{g}$ of DEAE-dextran (molecular weight, $2 \times 10^{6}$ ) per $\mathrm{ml}, 0.1 \mathrm{mM}$ chloroquine, and $10 \mu \mathrm{g}$ of supercoiled plasmid DNA per $\mathrm{ml}$, all in DME/H. After incubation for 30 to $60 \mathrm{~min}$ at $37^{\circ} \mathrm{C}$ in $7 \% \mathrm{CO}_{2}$, cells were pelleted, washed, and plated into 4 to 12 identical cultures. Approximately $20 \mathrm{~h}$ after plating, cells were stimulated with TPA and A23187 at final concentrations of 10 and $37 \mathrm{ng} / \mathrm{ml}$, respectively. These dosages were previously determined to be optimal for both IL-2 mRNA expression and secretion over 18 to $20 \mathrm{~h}$ in the population overall. Some of the cells also received IL-1 to the indicated concentrations. Human recombinant IL- $1 \alpha$ was found to be as effective as the mouse version on EL4.E1 cells and was used in most experiments.

Cells were harvested after various times of stimulation, and extracts from equivalent numbers of cells were assayed for CAT activity in a 5-h assay as described previously (29).

RNA analysis. Cytoplasmic RNA was extracted by the method of Favaloro et al. (12). The RNA from equivalent cell numbers was electrophoresed in denaturing $1 \%$ agaroseformaldehyde gels, stained with acridine orange to visualize the rRNA, and then blotted onto nylon membranes (Nytran; Schleicher \& Schuell). The RNA was fixed to the membrane by baking at $80^{\circ} \mathrm{C}$ for $60 \mathrm{~min}$. Hybridization probes were generated by random priming of cDNAs for mouse IL-2 (46) and mouse skeletal $\alpha$-actin (S. Sharp and N. Davidson, unpublished data) as described elsewhere (30). Hybridiza- tions were carried out for $20 \mathrm{~h}$ at $42^{\circ} \mathrm{C}$ in $5 \times$ SSPE-50\% formamide- $0.2 \%$ sodium dodecyl sulfate (SDS)-5 $\times$ Denhardt solution-10\% dextran sulfate. Filters were washed three times at room temperature for 1 min each in $2 \times \operatorname{SSC}$ (SSC is $0.15 \mathrm{M} \mathrm{NaCl}$ plus $0.015 \mathrm{M}$ sodium citrate- $0.2 \%$ SDS- $0.05 \%$ sodium pyrophosphate, followed by two 30-min washes at $68^{\circ} \mathrm{C}$ in $0.2 \times \mathrm{SSC}-0.1 \%$ SDS $-0.05 \%$ sodium pyrophosphate. Filters were exposed to film at $-70^{\circ} \mathrm{C}$ with an intensifying screen, and autoradiograms in the linear response range were densitometrically scanned. The amount of IL-2 mRNA was normalized with respect to the actin signal.

cAMP determination. EL4.E1 cells were resuspended in medium at a concentration of $1.2 \times 10^{6} / \mathrm{ml}$ and were stimulated at $37^{\circ} \mathrm{C}$ as indicated in Table 2 . Cell extracts were assayed for cyclic AMP (cAMP) by using a competition binding assay (RPA.509; Amersham) as described elsewhere (T. J. Novak and E. V. Rothenberg, Proc. Natl. Acad. Sci. USA, in press). Extracts were acetylated before assay to increase sensitivity.

Nuclear extracts. Nuclear proteins were extracted according to published procedures $(6,8 ; G$. Crabtree, personal communication) from cells that had been stimulated for 3 to $4 \mathrm{~h}$ under the conditions described for Fig. 4 and Table 3. Proteins extracted by either method gave similar results in gel mobility shift assays, and the data presented in Table 4 were obtained by using both types of extraction protocols. Extracts were stored at $-80^{\circ} \mathrm{C}$ until use.

Gel mobility shift assay. Mobility shift assays were carried out essentially as described elsewhere (3), with minor modifications. Synthetic double-stranded oligonucleotides were end labeled by filling in with either ${ }^{35} \mathrm{~S}$ - or ${ }^{32} \mathrm{P}$-labeled dTTP and dATP. For binding assays, 2.5 to $5.0 \mu \mathrm{g}$ of nuclear protein was incubated for $15 \mathrm{~min}$ at $25^{\circ} \mathrm{C}$ with $\sim 0.1 \mathrm{ng}$ of probe in the presence of a nonspecific competitor, usually $0.5 \mu \mathrm{g}$ of poly $(\mathrm{dI} \cdot \mathrm{dC})$ for NF-kB, 0.25 to $0.5 \mu \mathrm{g}$ of poly(dI . dC) for AP-1 $1_{D}$ and $A P-1_{P}$, or 2.5 to $10 \mu \mathrm{g}$ of poly $(\mathrm{dA} \cdot \mathrm{dT})$ for NFAT-1.

Complexes were separated from free probe by electrophoresis through $8 \%$ acrylamide gels which were cast and run in low-ionic-strength buffer. Gels were dried and exposed to film at $-70^{\circ} \mathrm{C}$ with intensifying screens. For experiments with ${ }^{35} \mathrm{~S}$-labeled probes, gels were fixed in Amplify (Amersham) and complexes were detected by fluorography.

For competition binding studies, 2.5 to $5.0 \mu \mathrm{g}$ of nuclear extract was preincubated for $15 \mathrm{~min}$ at $25^{\circ} \mathrm{C}$ with the indicated molar excess of competitor DNA (either a synthetic oligonucleotide or a cloned genomic fragment) before addition of labeled probe.

The synthetic oligonucleotides contained the binding sites for NFAT-1, NF-kB, AP- $1_{P}$ and AP- $1_{D}$ as found upstream of the mouse IL-2 gene (30) and were of the following sequences (coding strands on top):

$\begin{array}{ll}\begin{array}{l}\text { AP-1 consensus } \\ \text { (Stratagene) }\end{array} & \begin{array}{l}\text { 5'-CTAGTGATGAGTCAGCCGGATC-3' } \\ \text { 5'-GATCCGGCTGACTCATCAGTAG-3' } \\ \text { AP-1 }\end{array} \\ & \text { 5'-AATTCCAGAGAGTCATCAG-3' } \\ & \text { 5'-CTGATGACTCTCTGG-3' } \\ \text { AP-1 } & \\ & \text { 5'-AAATCCATTCAGTCAGTG-3' } \\ \text { NF-kB } & \text { 5'-CACTGTCTGAATGG-3' } \\ & \text { 5'-AAGAGGGATTTCACCT-3' } \\ & \text { 5'-ATTTAGGTGAAATCCCTCTT-3' } \\ \text { NFAT-1 } & \text { 5'-AAGAGGAAAATTGTTCATACAGAAGGCG-3' } \\ & \text { 5'-AATTCGCCTTCTGTATGAAACAAATTCCTCTT-3' }\end{array}$


TABLE 1. Effects of different stimuli on IL-2 production by EL4.E1 cells

\begin{tabular}{|c|c|c|}
\hline \multirow{2}{*}{ Stimulation $^{a}$} & \multicolumn{2}{|c|}{ IL-2 titer $(\mathrm{U} / \mathrm{ml})^{b}$} \\
\hline & Expt 1 & Expt 2 \\
\hline None & $<4$ & $<4$ \\
\hline TPA & 256 & 386 \\
\hline IL-1 & $<4$ & $<4$ \\
\hline TPA + A23187 & 307 & 448 \\
\hline TPA + A23187 + IL-1 & 1,280 & 614 \\
\hline $\mathrm{TPA}+\mathrm{A} 23187+$ forskolin & 106 & 204 \\
\hline
\end{tabular}

${ }^{a}$ Cells were incubated for $20 \mathrm{~h}$ in the presence or absence of TPA (35 nM), A23187 $(140 \mathrm{nM})$, IL-1 $(20 \mathrm{U} / \mathrm{ml})$, and forskolin $(10 \mu \mathrm{M})$. Confirmation of the inhibitory effects of forskolin at the RNA level is presented by Novak and Rothenberg (in press).

$b$ Titer in supernatants, determined by colorimetric assay on CTLL-2 cells as previously described (36). The presence of IL-1 in the assay supernatants has no effect on the indicator cells (36), and the addition of forskolin did not interfere with the quantitative detection of IL-2 in a control experiment (after adjustment to $10 \mu \mathrm{M}$ forskolin, a sample with $450 \mathrm{U}$ of IL-2 per ml gave a titer of $530 \mathrm{U}$ of IL-2 per $\mathrm{ml}$ in this assay; E. V. Rothenberg, unpublished data).

\section{RESULTS}

IL-1 is a costimulus for IL-2 expression by phorbol esterand ionophore-treated EL4.E1 cells. The EL4.E1 thymoma is a convenient murine model for studies of IL-2 gene expression, but it differs from normal $\mathrm{T}_{\mathrm{H}} 1$ cells in several ways. First, it is responsive to TPA alone. $\mathrm{A} \mathrm{Ca}^{2+}$ costimulus elicits higher levels of IL-2 but is not required. Second, unlike normal mature $\mathrm{T}$ cells (35), it shows synergy between IL-1 and TPA + A23187. These features are illustrated in Table 1, which presents typical yields of IL-2 from EL4.E1 cells after $20 \mathrm{~h}$ of stimulation under different conditions. The addition of calcium ionophore generally increased the levels of IL-2 relative to those elicited by TPA alone, to a maximum level that could not be surpassed by increasing the doses of TPA + A23187 (data not shown). The further addition of IL-1, however, resulted in even higher levels of IL-2 secretion. Nevertheless, IL-1 alone did not stimulate any detectable production of IL-2. Thus, the effect of IL-1 in these cells was to potentiate the effects of the TPA and A23187 stimuli on IL-2 synthesis. Such a potentiation could operate at pretranscriptional, posttranscriptional, or posttranslational levels. To dissect the basis for these differences in cumulative IL-2 synthesis over $20 \mathrm{~h}$, we examined the time course of IL-2 RNA accumulation.

The accumulation of IL-2 transcripts in EL4.E1 cells stimulated with TPA + A23187 alone was rapid and bimodal (Fig. 1A, lanes 2, 6, and 10). IL-2 mRNA levels peaked around $5 \mathrm{~h}$ and declined slowly during the next $13 \mathrm{~h}$. Costimulation of EL4.E1 cells with 2.5 or $20 \mathrm{U}$ of IL-1 per $\mathrm{ml}$ resulted in a two- or sixfold increase, respectively, in IL-2 mRNA at $5 \mathrm{~h}$ (Fig. 1A, lanes 1 to 4 ). This effect was primarily observed at early times of stimulation. At $12 \mathrm{~h}$ the enhancement due to IL-1 was only 1.5-fold (Fig. 1A, lanes 6 to 9),

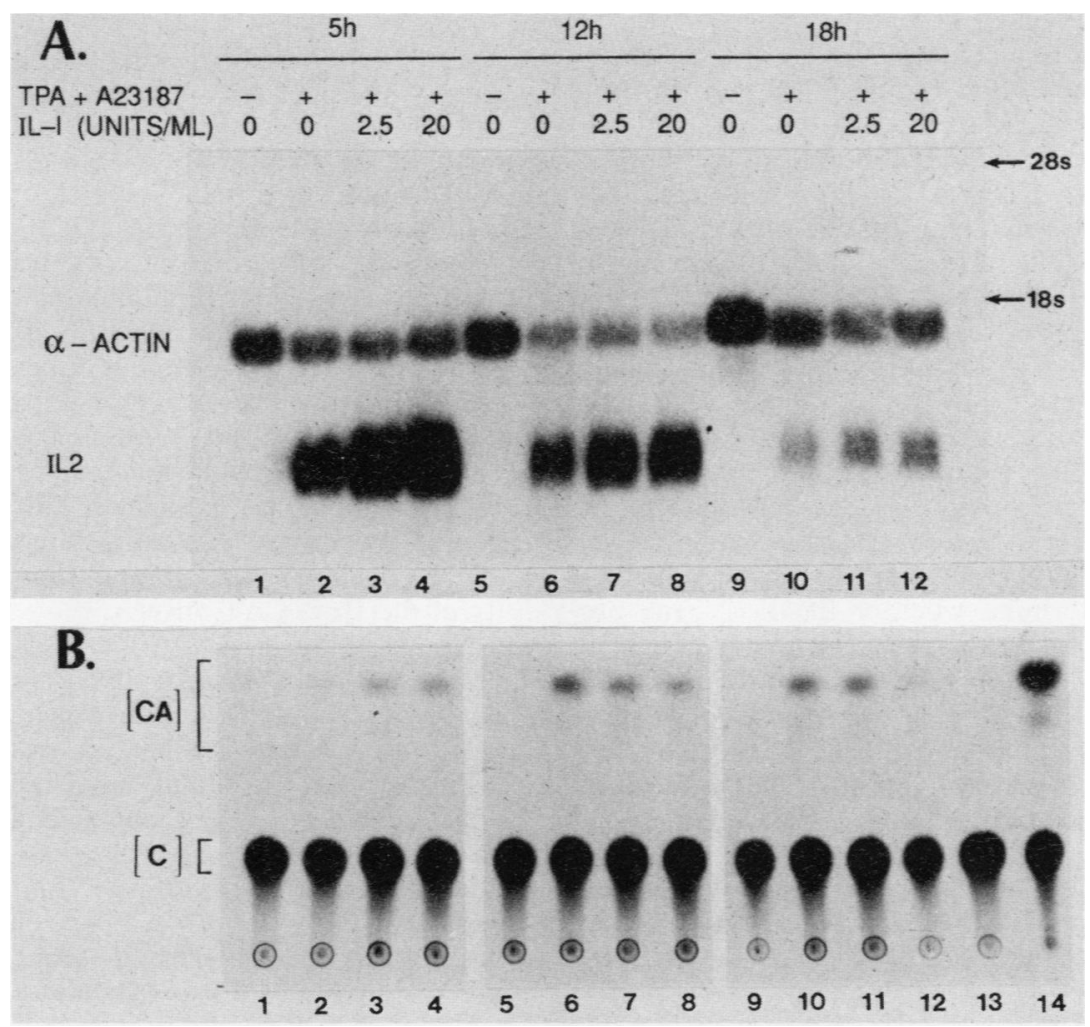

FIG. 1. IL-1 costimulation of IL-2 induction: effects on the IL-2 promoter. (A) Gel blot of cytoplasmic RNA extracted from unstimulated or stimulated EL4.E1 cells. Cells were stimulated as indicated for 5 to $18 \mathrm{~h}$, and RNA from $10^{6}$ cells was extracted, electrophoresed on a denaturing $1 \%$ agarose-formaldehyde gel, transferred to a nylon membrane (Nytran), and hybridized to cDNA probes for IL-2 and skeletal $\alpha$-actin. (B) CAT assay of extracts from EL4.E1 cells transfected with pIL2(-2800). Cells were stimulated as for panel A. Each lane represents the extract from transfected cells stimulated under conditions identical to those of the sample used for the corresponding lane of the RNA gel blot. Extracts were assayed at $37^{\circ} \mathrm{C}$ for $5 \mathrm{~h}$. Lanes 13 and 14 represent negative and positive assay controls, respectively. Positive control contains commercial CAT enzyme. [C], Unacetylated chloramphenicol; [CA], monoacetylated chloramphenicol. 
A. EL4.EI

- TPA + A23187

- TPA + A23187 + $20 \mathrm{~W} / \mathrm{mLIL1}$

\section{B. JURKAT}

-,0 TPA + A23187

$\triangle \triangle \mathrm{TPA}+\mathrm{A23187}+20 \mathrm{w} / \mathrm{m} / \mathrm{IL} 1$
pIL2 (-321)

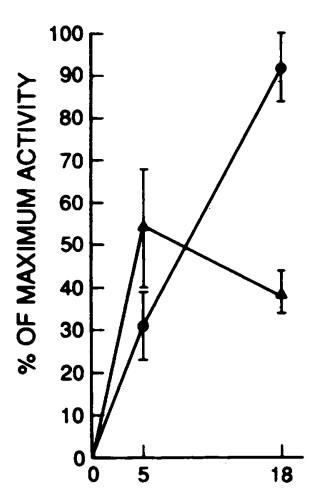

PIL2 (-1890)

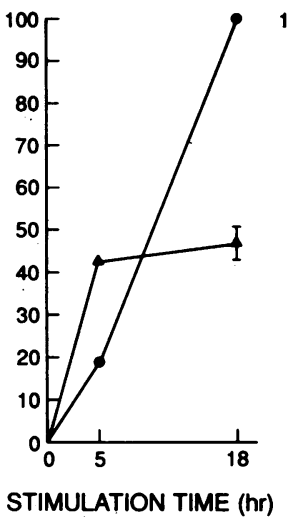

pIL2 (-2800)

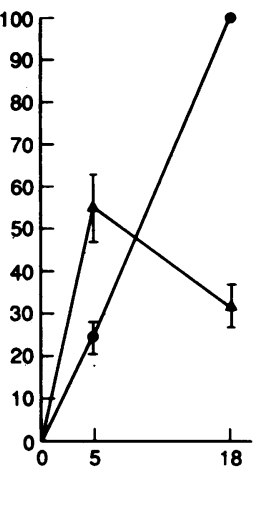

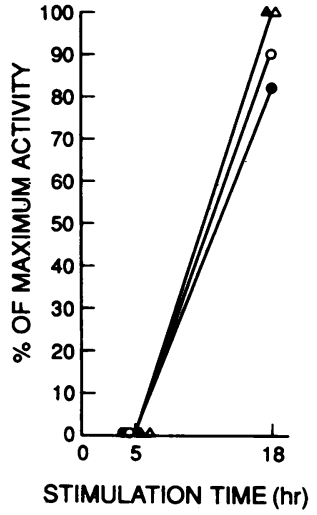

FIG. 2. Normalized time courses of IL-2-CAT expression in the presence or absence of recombinant IL-1 $\alpha$. (A) Time courses for EL4.E1 cells transfected with pIL2 $(-321)$, pIL2 $(-1890)$, and pIL2(-2800). Calculations for each plasmid were done separately. Each experiment consisted of six datum points: $5 \mathrm{~h}, 12 \mathrm{~h}$ (data not shown), and $18 \mathrm{~h}$ stimulated $\pm 20 \mathrm{U}$ of human recombinant IL-1 $\alpha$ per ml. CAT activity per $10^{6}$ cells was normalized with respect to the highest value in that experiment (in all but one case this was the 18-h sample without IL-1). Results are the means \pm standard errors of the mean of two to five separate experiments except for the pIL2(-1890) 5-h values, which were determined in one time course. (B) Normalized CAT assay curve for transfected Jurkat cells. Experimental conditions and calculations were exactly as for panel A. Open symbols, pIL2(-321); closed symbols, pIL2(-2800). Data are from one experiment.

and by $18 \mathrm{~h}$ IL-1 ceased to augment the level of steady-state IL-2 mRNA (Fig. 1A, lanes 9 to 12). The early increase and later loss of IL-2 RNA makes it likely that IL-1 costimulation increases the transcription rate but not RNA stability or translational efficiency.

No IL-2 mRNA was detected when EL4.E1 cells were stimulated for $5 \mathrm{~h}$ with $20 \mathrm{U}$ of IL-1 per $\mathrm{ml}$ in the absence of TPA, alone or in combination with $37 \mathrm{ng}$ of A23187 per ml (not shown). This inability to respond to IL-1 plus ionophore is in contrast to results reported by others for several IL-1-independent cell lines $(43,47)$, possibly because of the lower concentration of ionophore used here $(37 \mathrm{ng} / \mathrm{ml}=70$ $\mathrm{nM}$, compared with 250 to $500 \mathrm{nM}$ ). The failure of IL-1 to substitute for TPA suggests that it cannot duplicate the effects of TPA on protein kinase $C$.

Costimulatory effects of IL-1 are mediated through the IL-2 gene promoter. To determine whether the IL-2 gene promoter was responsible for mediating this positive effect, we used a series of pIL2-CAT plasmids that contains various lengths of IL-2 5'-flanking DNA, including the transcriptional start site, driving expression of CAT (30). In this way we could assay transcriptional initiation without concern for regulatory variations in mRNA stability (22) since, unlike authentic IL-2 mRNA, the CAT 3' untranslated region does not contain the AUUUA motifs that target lymphokine transcripts for rapid degradation $(33,38)$. Note that the CAT assay measures the translation product of the induced RNA, not the RNA directly.

Transfection experiments using IL2-CAT plasmids sug gest that IL-1 can increase the rate of transcription from the IL-2 gene promoter, even in cells optimally stimulated with TPA and ionophore. Several pIL2-CAT plasmids were transfected into EL4.E1 cells along with pRSV-CAT as a positive control. CAT activity was measured after 5,12 , and $18 \mathrm{~h}$ of stimulation with TPA and A23187 in the presence and absence of IL-1 (Fig. 1B and 2). A CAT assay of cells transfected with pIL2 $(-2800)$ is shown in Fig. 1B. Expression of the transfected IL-2-CAT gene required an appropriate inductive signal because unstimulated cells contained no enzyme activity (Fig. 1B, lanes 1, 5, and 9). Thus, even when introduced as a naked DNA template, the IL-2 gene promoter was not promiscuously transcribed in these cells. EL4.E1 transfectants stimulated with TPA plus A23187 contained easily detectable CAT activity at $5 \mathrm{~h}$ (Fig. 1B, lane 2), which would be expected if the peak in endogenous IL-2 mRNA seen at this time resulted from transcriptional activation of the IL-2 gene promoter. CAT activity in these cells continued to rise over the next $13 \mathrm{~h}$, reaching a maximum at $18 \mathrm{~h}$, the latest time examined. This increase in CAT activity occurred even as the steady-state level of endogenous IL-2 mRNA dropped (Fig. 1A), possibly indicating greater stability of the IL-2-CAT mRNA.

The addition of IL-1 to the stimulation regimen had two dramatic effects. First, cells stimulated in the presence of IL- 1 contained up to 2.5 times as much CAT activity per cell at $5 \mathrm{~h}$ as did those stimulated with TPA and A23187 alone (Fig. 1B, lanes 1 to 4, and Fig. 2A). This effect was IL-1 dose dependent because the enhancement was greater with 20 than with $2.5 \mathrm{U} / \mathrm{ml}$.

Second, the increase was transient, like the effect on endogenous IL-2 mRNA. Not only did IL-1 completely cease to enhance the steady-state level of IL-2 mRNA at 18 h (Fig. 1A, lanes 10 to 12 ), it also ceased to increase the amount of CAT activity per cell. In fact, CAT activity induced in the presence of IL-1 was now at least 60 to $70 \%$ lower than in cells stimulated without IL-1 (Fig. 2A). The mechanism of this late decrease is not fully understood but may be nonspecific. At $18 \mathrm{~h}$, the positive control plasmid, pRSV-CAT, was also expressed at levels $31 \%$ lower in cells costimulated with IL-1 than in cells stimulated without IL-1 
TABLE 2. Failure of IL-1 to increase cAMP in stimulated EL4.E1 cells

\begin{tabular}{|c|c|c|c|}
\hline \multirow{2}{*}{$\begin{array}{l}\text { Stimulation } \\
\text { conditions }^{a}\end{array}$} & \multirow{2}{*}{$\begin{array}{l}\text { Time } \\
(\min )\end{array}$} & \multicolumn{2}{|c|}{$\begin{array}{l}\text { cAMP concn } \\
\left(\mathrm{fmol} / 10^{6} \text { cells }\right)^{b}\end{array}$} \\
\hline & & Expt 1 & Expt 2 \\
\hline \multirow{4}{*}{$\begin{array}{l}\text { No stimulation } \\
\text { TPA + A23187 }\end{array}$} & & 350 & 320 \\
\hline & 15 & 300 & 320 \\
\hline & 30 & 250 & 310 \\
\hline & 60 & 271 & 380 \\
\hline \multirow{3}{*}{$\mathrm{TPA}+\mathrm{A} 23187+20 \mathrm{U}$ of $\mathrm{IL}-1 / \mathrm{ml}$} & 15 & 246 & 300 \\
\hline & 30 & 308 & 340 \\
\hline & 60 & 258 & 460 \\
\hline \multirow[t]{3}{*}{$\mathrm{TPA}+\mathrm{A} 23187+10^{-7} \mathrm{M}$ forskolin } & 15 & ND & 460 \\
\hline & 30 & ND & 470 \\
\hline & 60 & ND & 750 \\
\hline \multirow{3}{*}{$\mathrm{TPA}+\mathrm{A} 23187+10^{-5} \mathrm{M}$ forskolin } & 15 & ND & $>4,000$ \\
\hline & 30 & ND & $>4,000$ \\
\hline & 60 & ND & $>4,000$ \\
\hline
\end{tabular}

${ }^{a}$ EL4.E1 cells were stimulated with TPA $(10 \mathrm{ng} / \mathrm{ml})+\mathrm{A} 23187(37 \mathrm{ng} / \mathrm{ml})$ at a density of $1.2 \times 10^{6} / \mathrm{ml}$.

${ }^{b}$ Measured by using a commercial assay kit as described in Materials and Methods. All values are from assays with acetylated standards and samples. The high values for samples with $10^{-5} \mathrm{M}$ forskolin were corroborated by reassay with nonacetylated standards and samples. ND, Not done.

(see below and Table 3). By contrast, the early enhancement of CAT expression from the IL-2 gene promoter was promoter specific. Expression of pRSV-CAT in stimulated EL4.E1 cells was not affected by the presence of IL-1 when examined after 3 or $5 \mathrm{~h}$ of stimulation (unpublished data). This result suggests that at later times, IL-1 caused a general decrease in CAT expression, possibly via reduced translational efficiency, which was distinct from its promoterspecific transcriptional enhancing effects seen at $5 \mathrm{~h}$.

Possible mediators contributing to the effects of IL-1 on EL4.E1 cells. (i) IL-1R. The effects of IL-1 on the IL-2 gene promoter require the expression of IL-1R, as demonstrated by the results from identical transfection experiments using IL-1R ${ }^{-}$Jurkat cells instead of EL4.E1 cells. A time course of IL-2-CAT expression in Jurkat cells is shown in Fig. 2B. These cells showed much slower kinetics of expression of pIL2-CAT plasmids than did EL4.E1 cells. No activity was detected at $5 \mathrm{~h}$ even in the presence of $20 \mathrm{U}$ of IL-1 per ml. Cells had begun to express by $12 \mathrm{~h}$, and CAT activity was still rising by $18 \mathrm{~h}$. However, no significant effect, early or late, could be attributed to IL-1. These results provide evidence that surface expression of a canonical IL-1R is a prerequisite for the IL-1 effects that we have described. It is thus unlikely that the effects seen in EL4.E1 cells are due to the type of phosphatidylcholine hydrolysis reported to occur in Jurkat cells (34).

(ii) cAMP. It has been shown that IL-1 can utilize cAMP as an intracellular second messenger in a number of non-T-cell lines (42). Our results argue against a simple cAMP elevation mechanism as the pathway for IL-1 costimulation in EL4.E1 cells. First, IL-1 costimulation had minimal effects on cAMP levels in these cells (Table 2). Second, the effects of $20 \mathrm{U}$ of IL-1 per $\mathrm{ml}$ and $10 \mu \mathrm{M}$ forskolin were clearly different (Table 3). Expression of pRSV-CAT was enhanced at $18 \mathrm{~h}$ with forskolin but inhibited with the concentration of IL-1 used here. Whereas expression of pIL2(-321) was depressed at $18 \mathrm{~h}$ by both IL-1 and forskolin, the 5-h results clearly demonstrated the dissimilarity of these two stimuli. Forsko-
TABLE 3. Distinct effects of IL-1 and forskolin on expression of pRSV-CAT and pIL2(-321) in EL4.E1 cells

\begin{tabular}{cccc}
\hline Construct & $\begin{array}{c}\text { Stimulation } \\
\text { time } \\
(\mathrm{h})\end{array}$ & \multicolumn{2}{c}{ CAT activity $(\% \text { of control })^{a}$} \\
\cline { 3 - 4 } & 18 & $\begin{array}{c}+\mathrm{IL}-1 \\
(20 \mathrm{U} / \mathrm{ml})\end{array}$ & $\begin{array}{r}+10 \mu \mathrm{M} \\
\text { forskolin }^{b}\end{array}$ \\
\hline pRSV-CAT & 5 & $68 \pm 0.5$ & $427 \pm 99$ \\
pIL2(-321) & 18 & $169 \pm 22$ & $28 \pm 4$ \\
& $43 \pm 6$ & $51 \pm 17$ \\
\hline
\end{tabular}

${ }^{a}$ Cells were stimulated for the indicated lengths of time with TPA $(10 \mathrm{ng} / \mathrm{ml})$ + A23187 $(37 \mathrm{ng} / \mathrm{ml})$ in the presence or absence of IL-1 or forskolin. CAT activity per $10^{6}$ cell equivalents was determined, and the value for the drug-treated samples was normalized with respect to that of the drug-free control. Results are presented as means \pm standard errors of the mean or as means \pm ranges (in the cases with two experiments) of two to four experiments each.

${ }^{b}$ Results are presented in more detail elsewhere (Novak and Rothenberg, in press).

lin was even more suppressive at $5 \mathrm{~h}$ than at $18 \mathrm{~h}$, whereas IL-1 was stimulatory at this time point (Table 3; see also Fig. 1B, lanes 1 to 4 , and Fig. 2A). We have also shown that elevation of cAMP by a variety of other agents can depress IL-2 gene expression in a dose-dependent fashion (Novak and Rothenberg, in press), supporting the conclusion that elevation of cAMP levels per se has a net negative effect on IL-2 gene promoter function. While these results do not rule out cAMP-responsive signaling molecules as participants in the IL-1 enhancement pathway, they do show that the stimulatory effect of IL-1 is unlikely to be a result of any sustained increase in cAMP concentration.

IL-2 gene promoter sequences upstream of -321 are not required for IL-1 costimulation. Our previous work on the upstream region of the mouse IL-2 gene indicated the presence of several positive and negative regulatory elements between -321 and -2800 , any of which might be involved in IL-1-mediated effects. However, the data presented in Fig. 2A make it unlikely that far-upstream sequences are required.

When normalized for maximal levels of CAT activity, the kinetics of IL-1 costimulation for pIL2(-321), pIL2(-1890), and pIL2 $(-2800)$ were virtually superimposable (Fig. 2A). Thus, the degrees of both the 5-h enhancement and the 18-h suppression were unaffected by IL-2 5 '-flanking sequences extending upstream of -321 . It should be noted, however, that the absolute amount of CAT activity per cell at each time point was higher with pIL2 $(-1890)$ and pIL2 $(-2800)$ than with pIL2 $(-321)$, in accord with our previously reported results (30).

Further truncation of the IL-2 gene promoter region led to severe loss of inducibility, such that any IL-1-dependent enhancement was difficult to detect. We evaluated the responses of two plasmids with deletions in the region from -321 to -261 . One, pIL2(-232), failed to give significant expression with or without IL-1 at any time point. Expression of the other, pIL2 $(-1890 ; \Delta$ NFAT -1$)$, which bears a deletion from -261 to $-321(30)$, was also undetectable at 5 $h$ of stimulation, when IL-1 would be expected to exert a positive effect (P. M. White, T. J. Novak, and E. V. Rothenberg, unpublished results; 30). Thus, retention of sequences between -261 and -321 appeared to be essential for expression and IL-1 costimulation.

Effect of IL-1 costimulation on sequence-specific DNAbinding factors. The sequences from -50 to -300 in the human IL-2 gene include binding sites for several DNAbinding proteins of different specificities which have been implicated in regulation $(4,10)$. One factor, binding se- 


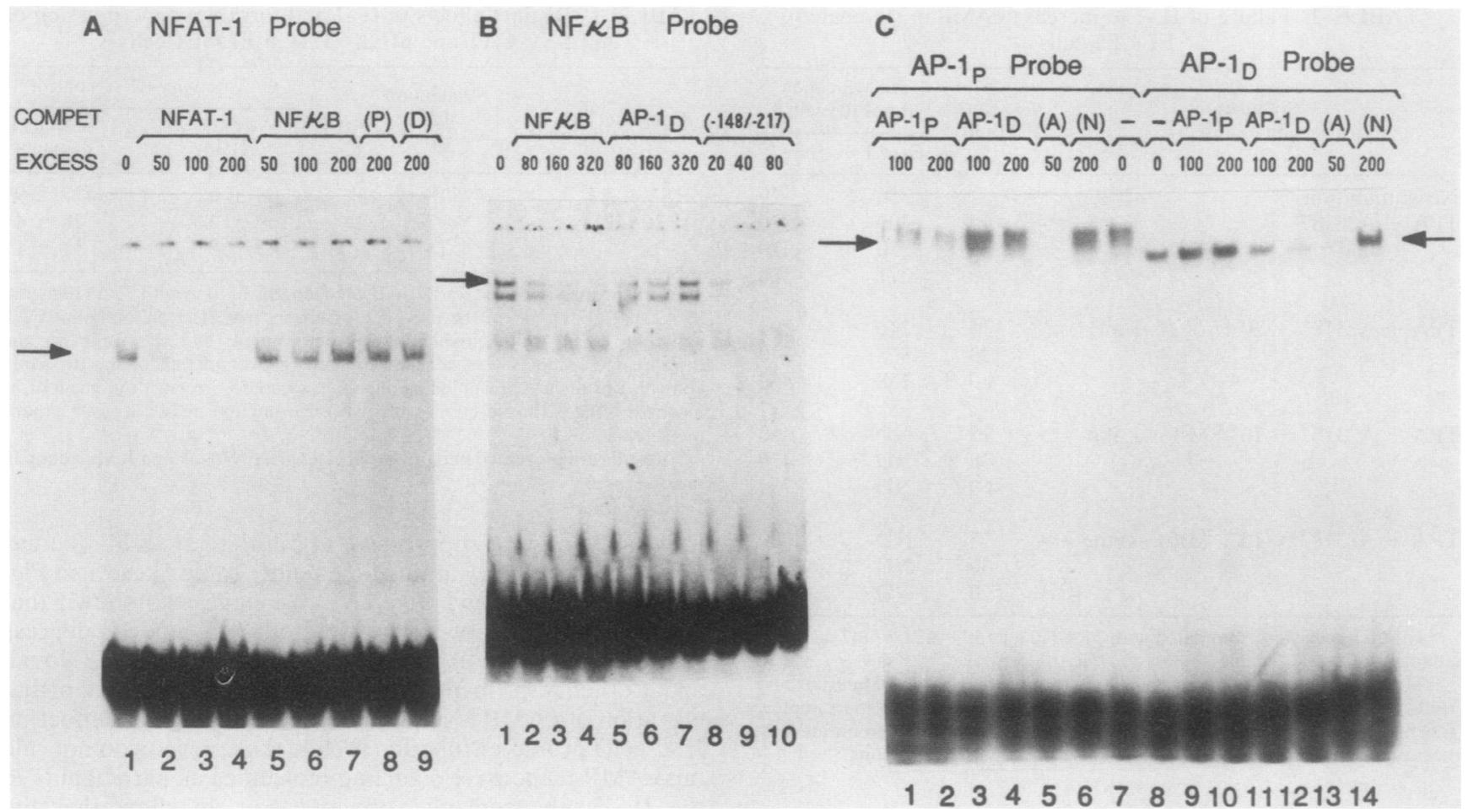

FIG. 3. Specificities of complexes with binding activity for IL-2 regulatory sequences. (A) Homologous and heterologous competition for the complex binding the NFAT-1 oligonucleotide. Competition gel shift assays were carried out as described in Materials and Methods with a labeled NFAT-1 oligonucleotide. Unlabeled competitor oligonucleotides were added as indicated, to 50- to 200-fold molar excesses. The arrow indicates the specific NFAT-1 complex. (P) and (D) represent the AP- $1_{P}$ and AP- $1_{D}$ oligonucleotides, respectively. Lane 1 , No specific competitor. Each lane contained $2.5 \mu \mathrm{g}$ of nuclear extract from cells stimulated with TPA + A23187 + IL-1 with $2.3 \mu \mathrm{g}$ of poly(dA $\cdot \mathrm{dT})$ as nonspecific competitor. (B) As panel A, using labeled NF-kB oligonucleotide with the indicated competitors at the molar excesses shown. Lane 1 , No specific competitor. $(-148 /-217)$ is a restriction fragment from the natural IL-2 gene promoter that contains the NF-kB site. Its greater potency as a competitor in part reflects a general effect of length (F. J. Calzone and E. H. Davidson, personal communication). Each lane contained $5 \mu \mathrm{g}$ of extract from TPA + A23187-stimulated cells and $0.5 \mu \mathrm{g}$ of poly $(\mathrm{dI} \cdot \mathrm{dC})$. (C) Cross-competition of complexes binding the AP-1 $1_{\mathrm{P}}$ and $\mathrm{AP}-1_{\mathrm{D}}$ oligonucleotides. Lanes: 1 to $7, \mathrm{AP}-1_{\mathrm{P}}$ probe with the indicated competitors (lane 7 , no specific competitor); 8 to 14 , AP- $1_{D}$ probe with the indicated competitors (lane 8, no specific competitor). (A) denotes a commercial consensus AP-1 22-mer (Stratagene), used at 50-fold molar excess; (N) denotes the NF-kB oligonucleotide used at 200-fold molar excess. Arrows indicate the mobilities of the main AP- $1_{P}$ complex (left) and the AP- $1_{D}$ complex (right). Each lane contained $5 \mu \mathrm{g}$ of extract as in panel A, with $0.125 \mu \mathrm{g}$ of poly(dI $\left.\cdot \mathrm{dC}\right)$. Both extracts used in this figure were made by the method of Dignam et al. (6).

quences from -66 to -90 , is the constitutive Oct-1 protein, which also appears to bind sequences between -240 and $-250(10)$. Factors whose binding activity is known to be dependent on cellular activation bind at -264 to -284 (NFAT-1) and -196 to -205 (NF-kB or a close relative) $(5$, $17,39)$. In addition, there are two potential sites for the binding of the canonical TPA-response factor AP-1 (2), although neither contains a perfect consensus sequence. One, from -186 to $-195\left(\mathrm{AP}-1_{\mathrm{D}}\right)$, has been proposed as a critical site for IL-1 effects in another cell line (26). The other, from -145 to $-153\left(\mathrm{AP}-1_{\mathrm{P}}\right)$, has been shown to bind a purified AP-1 factor (37).

To dissect the mechanism of IL-1 costimulation of EL4.E1 cells, we focused on the four sites for potentially inducible factors: NFAT-1, NF-kB, AP- $1_{D}$, and AP-1 $1_{P}$. Synthetic double-stranded oligonucleotides containing these sites as found in the murine IL-2 gene were used in gel retardation assays to detect DNA-binding proteins in nuclear extracts from EL4.E1 cells after different types of stimulation. Typical results, representative of four to seven independent analyses, are presented in Fig. 3 and 4. A summary is provided in Table 4.

Four distinct binding specificities. Confirmation of the distinct specificities of these factors is presented in Fig. 3.
The binding of NFAT-1 was highly sensitive to competition with its homologous target sequence and impervious to competition with the other oligonucleotides used (Fig. 3A). Figure 3B similarly confirms the specificity of the NF-kB complexes and their ability to be competed for by a longer IL-2 DNA fragment $(-148$ to -217$)$ that contains this site. We routinely observed a doublet of complexes binding the $\mathrm{NF}-\kappa \mathrm{B}$ site, both of which appear specific by competition analysis. Only the upper band was strongly induction dependent, however, and in the text that follows we will use "NF-кB" to refer only to this slower-migrating species.

The factors that bind to the two AP-1 sites are not identical, although their target sites are of related sequence. This conclusion was confirmed by the cross-competition analysis shown in Fig. 3C. First, the two complexes had different mobilities (compare lanes 7 and 8). Second, it is clear that they had different binding preferences. Both were legitimately capable of binding a commercial consensus AP-1 oligonucleotide (Fig. 3C, lanes 5 and 13), and neither was detectably competed for by the NF- $\mathrm{BB}$ site oligonucleotide (lanes 6 and 14). However, while the AP- $1_{P}$ oligonucleotide competed for the complex binding its homologous sequence (lanes 1 and 2 ), it did not compete for the AP- $1_{D}$ complex (lanes 9 and 10). Correspondingly, the AP-1 


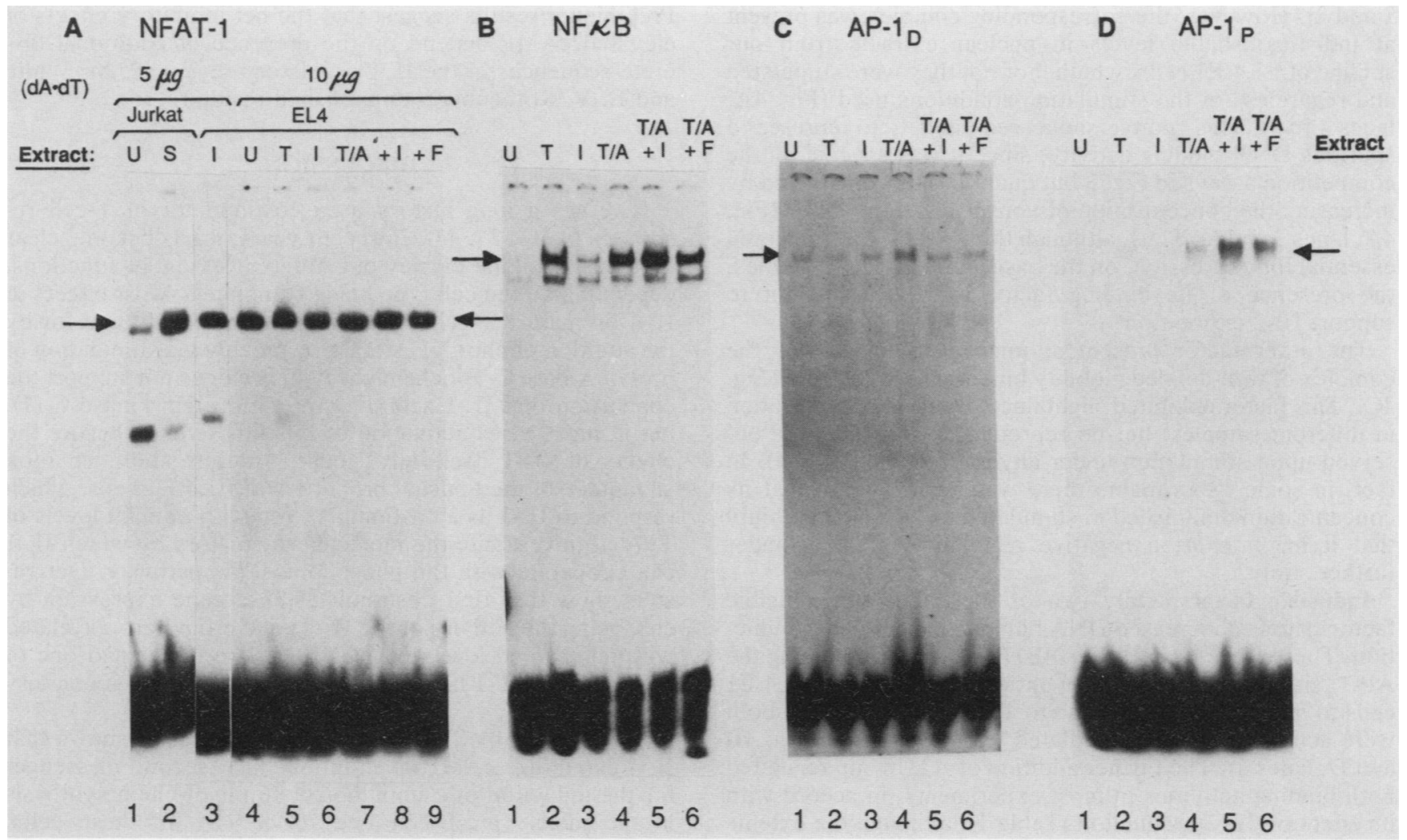

FIG. 4. Differential activation of IL-2 DNA-binding factors under different conditions of stimulation. In each panel, the indicated probes were used for gel shift analysis, each lane containing $5 \mu \mathrm{g}$ of extract from EL4.E1 cells that were stimulated for $3.5 \mathrm{~h}$ under the indicated conditions: U, unstimulated; T, TPA alone; I, IL-1 alone; T/A, TPA plus A23187; T/A+I, TPA plus A23187 plus IL-1; T/A+F, TPA plus A23187 plus $10 \mu \mathrm{M}$ forskolin. In panel A only, NFAT-1 complexes from EL4.E1 cells (lanes 3 to 9) are compared with complexes formed by nuclear extracts from Jurkat cells, either unstimulated (U) or stimulated with TPA plus A23187 (S). (A) NFAT-1 factor. The arrow indicates the NFAT-1 complex, which is inducible in Jurkat cells (lanes 1 and 2) but constitutive in EL4.E1 cells (lanes 4 to 9). Lane 3 contains a duplicate of the extract used in lane 6 with a lower amount of nonspecific competitor, to demonstrate that the lower band seen in the Jurkat sample (lane 1) is nonspecific. (B) NF-kB factors. The arrow indicates the upper complex, which is more strictly dependent on induction than the lower complex and which is the subject of discussion in the text. Each lane contained $0.5 \mu \mathrm{g}$ of poly $(\mathrm{dI}-\mathrm{dC})$. (C) AP- $1_{\mathrm{D}}$ factor. The increased band intensity seen in lane 4 was highly irreproducible (see Table 4), in contrast to the differences seen in panel B. In panels $C$ and $\mathrm{D}, 0.25 \mu \mathrm{g}$ of poly $\left(\mathrm{dI} \cdot \mathrm{dC}\right.$ ) was used as nonspecific competitor. Arrows indicate the specific complexes. (D) AP-1 $1_{\mathrm{P}}$ factor, analysis as for panel C.

oligonucleotide showed homologous competition (lanes 11 and 12) but did not compete for the AP- $1_{P}$ complex (lanes 3 and 4). The quantitative reciprocity of these effects, as measured at 100- and 200-fold molar excess, rules out the trivial explanation that the two factors had identical specificities but were present at different concentrations in the nuclear extract. These results show that the two AP-1 factors are distinct both in size and in specificity. As discussed below, they are also distinct in regulation.

Constitutive factors. Two of the factors detected by these assays appeared to be expressed constitutively in the EL4.E1 thymoma cells. One, unexpectedly, was NFAT-1. A complex of the expected mobility (indicated by an arrow in Fig. 4A) was highly inducible in Jurkat cells (Fig. 4A, lanes

TABLE 4. Summary of effects of different stimulation conditions on specific IL-2 DNA-binding proteins

\begin{tabular}{|c|c|c|c|c|c|c|c|}
\hline \multirow{2}{*}{$\begin{array}{l}\text { DNA-binding } \\
\text { factor }\end{array}$} & \multicolumn{6}{|c|}{ Stimulation conditions ${ }^{a}$} & \multirow{2}{*}{$\begin{array}{l}\text { No. of } \\
\text { expts }^{b}\end{array}$} \\
\hline & $\mathrm{U}$ & $\mathrm{T}$ & $\mathbf{I}$ & $\mathbf{T} / \mathbf{A}$ & T/A+I & $T / A+F$ & \\
\hline NFAT-1 & $+/ \pm$ & + & + & + & + & + & $2(\mathrm{D})+3(\mathrm{C})$ \\
\hline$N F-k B^{c}$ & - & $++1+$ & $+/ \pm$ & $++1+$ & +++ & $++1+$ & $2(\mathrm{D})+2(\mathrm{C})$ \\
\hline $\mathrm{AP}-1_{\mathrm{D}}{ }^{c}$ & + & + & + & + & + & + & $2(\mathrm{D})+2(\mathrm{C})$ \\
\hline AP- $1_{\mathbf{P}}{ }^{c}$ & $\pm /-$ & + & - & ++ & +++ & +++ & $2(\mathrm{D})+2(\mathrm{C})$ \\
\hline
\end{tabular}

a Terminology as in the legend to Fig. 4.

${ }^{b}$ Number of independent experiments (separate stimulation and extract preparation), counting separately cases in which extracts were generated by the method of Dignam et al. (6) (D) or Crabtree (4) (C). Similar relative results were obtained with both kinds of extracts although the absolute concentrations of different factors were somewhat different for the two protocols.

$c$ One set of data was obtained from an experiment with extracts prepared by the method of Dignam et al. (6) which compared only the U, T, T/A, and T/A +1 conditions of culture. 
1 and 2). However, the corresponding complex was present at indistinguishable levels in nuclear extracts from our subline of EL4.E1 cells, whether or not they were stimulated and regardless of the stimulation conditions used (Fig. 4A, lanes 4 to 9). This complex appeared unlikely to represent a spurious DNA-binding activity, since it was specific by the competition assays in Fig. 3 but quantitatively unaffected by increasing the concentration of nonspecific competitor (Fig. 4A, lanes 3 and 6). Thus, although the NFAT-1 site appeared essential for expression, on the basis of our deletion studies, the presence of its binding factor was not sufficient to support IL-2 expression.

The other factor present at unchanged levels was the complex of well-defined mobility binding the AP- $1_{D}$ site (Fig. 4C). This factor exhibited slight fluctuations in concentration in different samples, but no reproducible increase was observed upon stimulation under any conditions (Table 4). In fact, in some experiments there was an indication that its concentration diminished in stimulated cells. The possibility that it might exert a negative regulatory effect is under further study.

Inducible factors. Only two of the candidate inducible factors showed increased DNA binding in response to induction. These were NF-kB (Fig. 4B) and the factor binding the AP- $1_{P}$ site (Fig. 4D). In agreement with the ability of EL4.E1 cells to make IL-2 in response to TPA alone (Table 1), both were activated in cells stimulated with TPA alone (Fig. 4B and D, lanes 2). The further addition of A23187 up regulated both binding activities in most experiments, in accord with its effect on IL-2 production (Table 1), although the extents of up regulation did not match precisely (Fig. 4B and D; compare lanes 2 and 4). The binding activities of both factors, however, were reproducibly enhanced further by addition of IL-1, which consistently yielded the highest levels observed of both complexes (Fig. 4B and D, lanes 5). This result was not due to additive activation of these factors by IL-1 and by TPA + A23187, for in most experiments IL-1 alone induced little or no binding activity of either type (compare lanes 3 in Fig. 4B and D). Thus, while IL-1 was only marginally and irreproducibly capable of activating either binding factor alone, it was a potent enhancer of the stimulating capacity of A23187 and TPA.

Summary. The results of multiple analyses of these four factors are collated in Table 4 . Overall, these data agree plausibly with the IL-2 titers reported in Table 1 , if it is assumed that all four factors are required for optimal promoter activity. The surprising, constitutive expression of NFAT-1 in this subline of cells, and possibly that of the AP- $1_{D}$ binding factor as well, may simply provide the biochemical explanation for the unique ability of EL4.E1 cells to express IL-2 in response to TPA alone. Nevertheless, this set of factors may not be sufficient to account for all regulatory modulation of IL-2 gene expression in EL4.E1 cells. As shown previously (Novak and Rothenberg, in press; Tables 1 and 3), $10^{-5} \mathrm{M}$ forskolin inhibits IL-2 induction by two- to threefold under these conditions. It is therefore surprising that forskolin, when added to TPA and A23187, induced effects on these DNA-binding proteins that were very similar to those of IL-1 (Fig. 4A, lane 9; Fig. 4B to $D$, lanes 6 ). While in several experiments the addition of forskolin appeared to decrease NF-кB expression selectively (data not shown), this effect was often modest (e.g., Fig. 4B). It is thus possible that the ratio of $A P-1_{P}$ to NF-kB affects expression. However, it seems more likely that the activity of the four putative positive regulators can be influenced by other regulatory proteins not examined here.
Preliminary results suggest that the net inhibitory effects of elevated CAMP depend on the presence of additional discrete sequences in the IL-2 regulatory region $(P$. M. White and E. V. Rothenberg, unpublished results).

\section{DISCUSSION}

IL-1 has a long history as a costimulator of T-cell responses $(9,13,25,44)$. In recent years, it has become clear that this cytokine carries out different essential functions, depending on the cell type being stimulated. Most effects of IL-1 on mature T cells, however, can be substituted for by the addition of phorbol esters, presumably via stimulation of protein kinase $\mathrm{C}$. Biochemical evidence does not support the conclusion that IL-1 acts directly via protein kinase C (1), but in most cases activation of this kinase can obscure the effects of IL-1 itself on T cells. In this study we took advantage of the unusual properties of EL4.E1 cells, which respond to IL-1 as a costimulus even with optimal levels of TPA, to investigate the molecular mediators by which IL-1 can cooperate with the phosphoinositide pathway. Our results show that IL-1 costimulates IL-2 gene expression by enhancing the activity of the IL-2 gene promoter, correlated with augmented levels of an NF-kB-like factor and one of two distinct AP-1-like factors that bind to IL-2 regulatory sequences.

Recent work by Shirakawa and colleagues has shown that IL-1 can utilize cAMP as an intracellular second messenger for the induction of $\mathrm{k}$ immunoglobulin light-chain synthesis in the mouse pre-B-cell line $70 \mathrm{Z} / 3$ (42). In these cells, IL-1-mediated induction coincides with the activation of a protein that can bind to the NF-кB consensus site in the 5 -flanking region of the $\kappa$-chain genes (40). NF- $k B$ is not the only transcription factor implicated in IL-1 effects, however. IL-1 can also induce transcription of the c-jun proto-oncogene, which encodes a component of AP-1, in the mouse IL-1-dependent T-cell line LBRM-331A5 (26). In that cell line, expression of a linked reporter gene from the human IL-2 promoter required an intact AP- 1 site at -185 relative to the transcriptional start site. However, the deletions tested which removed this site also removed the NF-kB site centered at $\mathbf{- 2 0 0}$. Therefore, the resulting loss of promoter function (26) cannot be attributed unequivocally to loss of this distal AP-1 site. In fact, deletion analysis of the human IL-2 gene promoter has not demonstrated an important role for this AP-1 site in vivo (8). Footprint analysis of the mouse IL-2 promoter has led to the same conclusion (37).

In several respects, our results are in agreement with these previous reports. Thus, our data support the interpretation that one mediator of the IL-1 effect may be NF-kB or a related factor $(31,40)$. The addition of IL-1 as a costimulus invariably augmented NF-kB binding activity over that induced by the cocktail of TPA and A23187, and in some experiments (e.g., Fig. 4) we could even detect enhanced NF-kB binding after stimulation with IL-1 alone. As expected if IL-1 activated NF-кB, it also enhanced the induction of IL-2 receptor $\alpha$-chain transcripts in the EL4.E1 cells (T. J. Novak and E. V. Rothenberg, unpublished results). Even the failure of IL-1 to affect IL-2 gene promoter activity in Jurkat cells is also consistent with its working through $\mathrm{NF}-\mathrm{kB}$, since in these cells IL-1 does not induce appearance of this DNA-binding protein (31). The resulting implication that NF-KB may be rate limiting for IL-2 induction is in accord with published evidence that mutation of the NF-kB site depresses IL-2 gene promoter function, relative to wild type, in optimally stimulated cells (17). 
In contrast to other cell types $(41,42)$, however, EL4.E1 cells appear to be able to respond to IL-1 as a costimulus without using cAMP as the principal mediator. As we report here and in more detail elsewhere (Novak and Rothenberg, in press), IL-2 gene promoter activity is significantly inhibited by treatments that cause a sustained elevation of intracellular cAMP. This inhibition is especially sharp at the early times when IL-1 is most potent in its stimulatory activity. Thus, the cooperative effects of IL-1 with phosphoinositide pathway stimulation and those of cAMP appear quite distinct.

It seems paradoxical, then, that both IL-1 and cAMP may enhance activation of NF- $\mathrm{KB}$. Indeed, both also hyperactivate the binding factor of the proximal AP-1 site. However, while the induced DNA-binding activities that we have studied probably participate in the mechanism regulating IL-2 gene promoter activity, they may not be the only components, or the only decisive components, of a combinatorial mechanism. The resolution of this paradox is most likely to come, therefore, from more extensive monitoring of the ensemble of regulatory proteins that control IL-2 gene expression, rather than a focus on any single one. Our results with only four such factors provide compelling evidence for the combinatorial nature of IL-2 gene regulation. The NFAT-1 factor, the regulation of which may be sufficient to account for the response to TcR ligands in Jurkat cells $(4,10)$ is not rate limiting in EL4.E1 cells. The NFAT-1-binding activity is present at maximal levels even in cells which cannot secrete IL-2 and cannot express IL-2 promoter constructs. Yet the cooperation of this factor appears to be required for efficient IL-2 induction, as shown by the minimal activity, with or without IL-1, of constructs from which its binding site has been deleted. In this context, the shared abilities of forskolin and IL-1 to stimulate the $\mathrm{AP}-1_{\mathrm{P}}$ factor and NF-KB imply less that these agents mediate the same signal than that the set of factors we monitor may be incomplete.

How can the costimulatory effects of IL-1 on AP-1 $P$ and NF- $\mathrm{B}$ B activation be explained? There are two general possibilities. First, IL-1/IL-1R triggering may directly induce activation of these two factors, and possibly others uniquely responsive to IL-1, mobilizing pools that are not accessible to the calcium ionophore/phorbol ester stimulation pathway. The effects of IL-1 would then be additive with those of the phosphoinositide pathway agonists, at the level of the DNAprotein contacts in chromatin. Another possibility is that the ability of A23187/TPA to activate these DNA-binding proteins is itself modulated by an intracellular gating function that is subject to IL-1 regulation. In this case, IL-1 need not induce any DNA-binding protein activities by itself in order to be a potent regulator of the efficiency with which the major activating pathway mobilizes gene expression. While too few factors have yet been examined to confirm or rule out the first mechanism, several of our findings lend plausibility to the second. First, IL-1 alone is strikingly poor at effecting any increase or decrease in the binding activity of any of the factors studied here. In EL4.E1 cells, it is far more potent as a costimulus than as a stimulus (see, e.g., Table 4). Second, the factors that IL-1 coactivates thus far appear to be only those that are activated in any case by A23187 and TPA. Third, our survey of IL-1 effects on the expression of IL-2 promoter constructs with widely differing numbers of positive and negative modulatory sites (30) indicates that all expressible constructs are affected in parallel. Thus, IL-1 may act in these cells by enhancing the potency of A23187 and TPA as inducing agents, its signals converging with the phosphoinositide pathway before the activation of the specific DNA-binding proteins.

The mechanism of IL-1 costimulation may help to illuminate key stages in the development of $\mathrm{T}$-cell functional competence. We have previously reported that immature thymocytes can activate the IL-2 gene, but only subject to an absolute requirement for IL-1 costimulation. The locus of the IL-1 effect may thus identify a stage-specific block to the exercise of function in immature cells which is later overcome by the complex physiology of positive selection in the thymus. Work is now under way to explore this possibility.

\section{ACKNOWLEDGMENTS}

We thank Jerry Crabtree for his generous provision of cells, protocols, and advice, Frank Calzone and Eric Davidson for their critical guidance and encouragement, Cherrie Leighton for excellent graphics, and Cathy Blagg and Renee Thorf for careful preparation of the manuscript.

Support for this work was provided by the Lucille P. Markey Charitable Trust and by Public Health Service grant CA 39605 from the National Cancer Institute to E.V.R. T.J.N. was supported in part by a predoctoral training grant from the Public Health Service, and D.C. gratefully acknowledges support from a Gordon Ross Medical Fellowship.

\section{LITERATURE CITED}

1. Abraham, R. T., S. N. Ho, T. J. Barna, and D. J. McKean. 1987. Transmembrane signaling during interleukin 1-dependent T-cell activation. J. Biol. Chem. 262:2719-2728.

2. Angel, P., M. Imagawa, R. Chiu, B. Stein, R. J. Imbra, M. J. Rahmsdorf, C. Jonat, P. Herrlich, and M. Karin. 1987. Phorbol ester-inducible genes contain a common cis element recognized by a TPA-modulated trans-acting factor. Cell 49:729-739.

3. Calzone, F. J., N. Thézé, P. Thiébaud, R.L. Hill, R. J. Britten, and E. H. Davidson. 1988. Developmental appearance-of factors that bind specifically to cis-regulatory sequences of a gene expressed in the sea urchin embryo. Genes Dev. 2:1074-1088.

4. Crabtree, G. R. 1989. Contingent genetic regulatory events in $T$ lymphocyte activation. Science 243:355-361.

5. Cross, S. L., N. F. Halden, M. J. Lenardo, and W. J. Leonard. 1989. Functionally distinct NF-kB binding sites in the immunoglobulin $\kappa$ and IL-2 receptor $\alpha$ chain genes. Science 244:466469.

6. Dignam, J. D., R. M. Lebovitz, and R. G. Roeder. 1983. Accurate transcription initiation by RNA polymerase II in a soluble extract from isolated mammalian nuclei. Nucleic Acids Res. 11:1475-1489.

7. Dinarello, C. A. 1989. Interleukin-1 and its biologically related cytokines. Adv. Immunol. 44:156-205.

8. Durand, D. B., J.-P. Shaw, M. R. Bush, R. E. Reployle, R. Belagaje, and G. R. Crabtree. 1988. Characterization of antigen receptor response elements within the interleukin-2 enhancer. Mol. Cell. Biol. 8:1715-1724.

9. Durum, S. K., J. A. Schmidt, and J. J. Oppenheim. 1985. Interleukin 1: an immunological perspective. Annu. Rev. Immunol. 3:263-287.

10. Emmel, E. A., C. L. Verweij, D. B. Durand, K. M. Higgins, E. Lacy, and G. R. Crabtree. 1989. Cyclosporin A specifically inhibits function of nuclear proteins involved in T-cell activation. Science 246:1617-1670.

11. Farrar, J. J., S. B. Mizel, J. Fuller-Farrar, W. L. Farrar, and M. L. Hilfiker. 1980. Macrophage-independent activation of helper T cells. I. Production of interleukin 2. J. Immunol. 125:793-798.

12. Favaloro, J., R. Treisman, and R. Kamen. 1980. Transcription maps of polyoma virus-specific RNA: analysis by two-dimensional nuclease S1 gel mapping. Methods Enzymol. 65:718-749.

13. Gillis, S., and S. B. Mizel. 1981. T-cell lymphoma model for the analysis of interleukin 1-mediated T-cell activation. Proc. Natl. Acad. Sci. USA 78:1133-1137.

14. Greenbaum, L. A., J. B. Horowitz, A. Woods, T. Pasqualini, 
E. P. Reich, and K. Bottomly. 1988. Autocrine growth of CD4 ${ }^{+}$ $T$ cells. Differential effects of IL-1 on helper and inflammatory $T$ cells. J. Immunol. 140:1555-1560.

15. Hackett, R. J., L. S. Davis, and P. E. Lipsky. 1988. Comparative effects of tumor necrosis factor- $\alpha$ and IL-1 $\beta$ on mitogen-induced $T$ cell activation. J. Immunol. 140:2639-2644.

16. Heckford, S. E., E. P. Gelmann, C. L. Agnor, S. Jacobson, S. Zinn, and L. A. Matis. 1986. Distinct signals are required for proliferation and lymphokine gene expression in murine $\mathrm{T}$ cell clones. J. Immunol. 137:3652-3663.

17. Hoyos, B., D. W. Ballard, E. Böhnlein, M. Siekevitz, and W. C. Greene. 1989. Kappa B-specific DNA binding proteins: role in the regulation of human interleukin-2 gene expression. Science 244:457-460.

18. Kaye, J., S. Gillis, S. B. Mizel, E. M. Shevach, T. R. Malek, C. A. Dinarello, L. B. Lachman, and C. A. Janeway, Jr. 1984. Growth of a cloned helper $\mathrm{T}$ cell line induced by a monoclonal antibody specific for the antigen receptor: interleukin 1 is required for the expression of receptors for interleukin 2 . J. Immunol. 133:1339-1345.

19. Koide, S., and R. M. Steinman. 1987. Induction of murine interleukin 1: stimuli and responsive primary cells. Proc. Natl. Acad. Sci. USA 84:3802-3806.

20. Kurt-Jones, E. A., S. Hamberg, J. Ohara, W. E. Paul, and A. K. Abbas. 1987. Heterogeneity of helper/inducer T lymphocytes. I. Lymphokine production and lymphokine responsiveness. J. Exp. Med. 166:1774-1787.

21. Lichtman, A. M., J. Chin, J. A. Schmidt, and A. K. Abbas. 1988. Role of interleukin 1 in the activation of T lymphocytes. Proc. Natl. Acad. Sci. USA 85:9699-9703.

22. Lindsten, T., C. H. June, J. A. Ledbetter, G. Stella, and C. B. Thompson. 1989. Regulation of lymphokine messenger RNA stability by a surface-mediated T-cell activation pathway. Science 244:339-343.

23. Mary, D., C. Aussel, C. Pelassy, and M. Fehlmann. 1988. IL-1 signaling for IL-2 production in T cells involves a rise in phosphatidylserine synthesis. J. Immunol. 141:3078-3080.

24. McGuire, K. L., J. A. Yang, and E. V. Rothenberg. 1988. Influence of activating stimulus on functional phenotype: interleukin-2 mRNA accumulation differentially induced by ionophore and receptor ligands in subsets of murine $\mathrm{T}$ cells. Proc. Natl. Acad. Sci. USA 85:6503-6507.

25. Mizel, S. B. 1982. Interleukin 1 and T cell activation. Immunol. Rev. 63:51-72.

26. Muegge, K., T. M. Williams, J. Kant, M. Karin, R. Chiu, A. Schmidt, U. Siebenlist, H. A. Young, and S. K. Durum. 1989. Interleukin-1 costimulatory activity on the interleukin-2 promoter via AP-1. Science 246:249-251.

27. Nau, G. J., D-K. Kim, and F. W. Fitch. 1988. Agents that mimic antigen receptor signaling inhibit proliferation of cloned murine T lymphocytes induced by IL-2. J. Immunol. 141:3557-3563.

28. Nishizuka, Y. 1984. The role of protein kinase $C$ in cell surface signal transduction and tumour promotion. Nature (London) 308:693-698.

29. Novak, T. J., and E. V. Rothenberg. 1986. Differential transient and long-term expression of DNA sequences introduced into T lymphocyte lines. DNA 5:439-451.

30. Novak, T. J., P. M. White, and E. V. Rothenberg. 1990. Regulatory anatomy of the murine interleukin-2 gene. Nucl. Acids Res. 18:4523-4533.

31. Osborn, L., S. Kunkel, and G. J. Nabel. 1989. Tumor necrosis factor $\alpha$ and interleukin 1 stimulate the human immunodeficiency virus enhancer by activation of the nuclear factor NF-
кB. Proc. Natl. Acad. Sci. USA 86:2336-2340.

32. Otten, G., K. C. Herold, and F. W. Fitch. 1987. Interleukin 2 inhibits antigen-stimulated lymphokine synthesis in helper $\mathrm{T}$ cells by inhibiting calcium-dependent signaling. J. Immunol. 139:1348-1353.

33. Reeves, R., T. S. Elton, M. S. Nissen, D. Lehn, and K. R. Johnson. 1987. Posttranscriptional gene regulation and specific binding of the nonhistone protein HMG-I by the 3' untranslated region of bovine interleukin 2 cDNA. Proc. Natl. Acad. Sci. USA 84:6531-6535.

34. Rosoff, P. M., N. Savage, and C. A. Dinarello. 1988. Interleukin-1 stimulates diacylglycerol production in T lymphocytes by a novel mechanism. Cell 54:73-81.

35. Rothenberg, E. V., R. A. Diamond, T. J. Novak, K. A. Pepper, and J. A. Yang. 1990. Mechanisms of effector lineage commitment in T-lymphocyte development. UCLA Symp. Mol. Cell. Biol. 125:225-249.

36. Rothenberg, E. V., R. A. Diamond, K. A. Pepper, and J. A. Yang. 1990. Interleukin-2 gene inducibility in T cells prior to T-cell receptor expression: changes in signalling pathways and gene expression requirements during intrathymic maturation. $J$. Immunol. 144:1614-1624.

37. Serfling, E., R. Barthelmäs, I. Pfeuffer, B. Schenk, S. Zarius, R. Swoboda, F. Mercurio, and M. Karin. 1988. Ubiquitous and lymphocyte-specific factors are involved in the induction of the mouse interleukin 2 gene in T lymphocytes. EMBO J. 8:465473.

38. Shaw, G., and R. Kamen. 1986. A conserved AU sequence from the $3^{\prime}$ untranslated region of GM-CSF mRNA mediates selective mRNA degradation. Cell 46:659-667.

39. Shaw, J.-P., P. J. Utz, D. B. Duncan, J. J. Toole, E. A. Emmel, and G. R. Crabtree. 1988. Identification of a putative regulator of early $T$ cell activation genes. Science 241:202-205.

40. Shirakawa, F., M. Chedid, J. Suttles, B. A. Polk, and S. B. Mizel. 1989. Interleukin 1 and cyclic AMP induce $\kappa$ immunoglobulin light-chain expression via activation of an NF-kB-like DNA-binding protein. Mol. Cell. Biol. 9:959-964.

41. Shirakawa, F., and S. B. Mizel. 1989. In vitro activation and nuclear translocation of NF-kB catalyzed by cyclic AMPdependent protein kinase and protein kinase C. Mol. Cell. Biol. 9:2424-2430.

42. Shirakawa, F., U. Yamashita, M. Chedid, and S. B. Mizel. 1988. Cyclic AMP - an intracellular second messenger for interleukin 1. Proc. Natl. Acad. Sci. USA 85:8201-8205.

43. Simon, P. L. 1984. Calcium mediates one of the signals required for interleukin 1 and 2 production by murine cell lines. Cell. Immunol. 87:720-726.

44. Smith, K. A., K. J. Gilbride, and M. F. Favata. 1980. Lymphocyte activating factor promotes $\mathrm{T}$ cell growth factor production by cloned murine lymphoma cells. Nature (London) 287:853855 .

45. Williams, T. M., L. Eisenberg, J. E. Burlein, C. A. Norris, S. Pancer, D. Yao, S. Burger, M. Kamoun, and J. A. Kant. 1988. Two regions within the human IL-2 gene promoter are important for inducible IL-2 expression. J. Immunol. 141:662-666.

46. Yokota, T., N. Arai, F. Lee, D. Rennick, T. Mosmann, and K.-I. Arai. 1985. Use of a cDNA expression vector for isolation of mouse interleukin 2 cDNA clones: expression of T-cell growthfactor activity after transfection of monkey cells. Proc. Natl. Acad. Sci. USA 82:68-72.

47. Zlotnik, A., and B. Daine. 1986. Activation of IL1-dependent and IL1-independent $T$ cell lines by calcium ionophore and phorbol ester. J. Immunol. 136:1033-1037. 